\title{
Ideologias de conveniência em Educação
}

Carlos Vilar Estêvão a

Sempre assisti, com interesse renovado, às vicissitudes das políticas educativas, nomeadamente, quando elas enveredam por "ideologias de conveniência" que nos fazem sentir bem e reconfortam a nossa alma e a alma da Educação. É o caso das ideologias da modernização, da qualidade, da excelência, do mérito, ou então, da descentralização, da autonomia, da equidade, da democratização, da formação, das competências, da avaliação, entre muitas outras, que parecem, em determinados momentos, ser portadoras de novas mensagens, muito regeneradoras e redentoras.

O que surpreende é que elas emergem, de facto, como surtos salvíficos, que apontam para um mundo educativo novo, mais próspero, e onde o Estado pode, tranquilamente, assentar-se junto às margens do rios da Babilónia, não a chorar, como no salmo 137 do Antigo Testamento, mas a refazer-se dos ataques que foram, e são, feitos ainda à sua autoridade e legitimidade e a usufruir da brisa que, em geral, tende a agitar a sua táctica, mas não a sua estratégia (HARTLEY, 2001) sobre a Educação. Obviamente que, a ameaça dos ventos da globalmania se fizer sentir, tal como hoje acontece, acompanhada da economização crescente da vida social, e da própria crise do Estado, haverá, então, mais compreensão para o momentâneo apagamento, ou descanso do Estado, embora este não prescinda nunca do seu poder de prescrição e de controlo, ainda que mais sofisticadamente dissimulado e à distância.

Nos textos que compõem este número da Ensaio, também emergem problemáticas e inquietações em torno da formação, da aprendizagem, da equidade, da massificação, da democratização da gestão, da educação técnica, das tecnologias, da avaliação, que não podem deixar, em certos aspectos, de ser analisadas à luz do que ficou já dito, pese, embora, o facto de os autores se posicionarem aqui de uma forma ponderada, bem sustentada e crítica.

\footnotetext{
a Universidade Católica Portuguesa, Faculdade de Filosofia e Ciências Sociais, Braga, Portugal.
} 
Sabemos, por exemplo, que a instituição chamada formação, sobretudo na vertente das competências, tem vindo a impor-se com os seus mitos, reivindicada em nome das virtudes intrínsecas que colocam o portador (o formando) em primeiro lugar na grelha de partida na corrida pelo emprego e pela excelência. Aqui, pouco importa que o formando, ou o aprendente, seja cidadão, mas, antes, que o cidadão se torne aprendente eterno e contínuo, porque o mundo, altamente competitivo de hoje, exige indivíduos dotados com um motor de alto rendimento e formativamente bem oleado, para, desse modo, ganhar vantagens em termos de empregabilidade. Então, defendo que a ideologia da formação, e especificamente a das competências, nem sempre se tem traduzido num acréscimo de empowerment dos seus beneficiários, podendo, em alguns casos, representar, pelo contrário, um verdadeiro sacrifício para se manter em estado permanente de prontidão e de responsabilidade (e, por vezes, de autoexploração). Particularmente interessante para uma visão crítica da formação é o artigo de Roberto Silva, neste número da Ensaio, que desenvolve "A individualização dos percursos formativos como princípio organizador das políticas curriculares para o Ensino Médio no Brasil", assim como o de O. Turra-Díaz e C. Flores-Lueg, sobre "La formación práctica desde las voces del estudiantado de pedagogía", este último para questionar, sobretudo, o sentido do que deve entender-se por uma formação prática. Também o artigo de Conceição Barros, Ana Dias e Augusto Cabral, intitulado "Ações de formação docente institucionais", pode ser lido como a potenciação pela formação do poder do professor universitário, que tem no conhecimento e na maestria pedagógicos uma fonte de diferenciação profissional e de empoderamento.

Do mesmo modo, outras ideologias ligadas frequentemente à democratização da Educação podem padecer de enviesamentos que as distorcem na sua orientação. Tal será o caso, por exemplo, das políticas de massificação e universalização de subsectores do sistema de ensino, que podem, em nome da inclusão e da equidade, preocupar-se quase exclusivamente com a "mcdonaldização" do sistema (ver o artigo de Gerardo Serpa e Adriana Falcón nesta Ensaio, que, a propósito dessa expressão, referem Hayes e Wynyard, 2002); ou então, o caso de se apelidar de democrática uma gestão escolar que pouco pode ter a ver com a participação, sobretudo se ela degenerar para o gerencialismo, que transforma a participação em encenação participativa ou em mera técnica gestionária, pensada para aumentar a produtividade. Sobre este ponto, revela-se particularmente recomendável a leitura, nesta edição, do artigo de Ângelo Souza, sobre "As condições de democratização da gestão da escola pública brasileira". Do mesmo modo, e para se aprofundar a questão da ideologia da democratização, será certamente estimulante a leitura do artigo de Arão Oliveira, Valdivina Ferreira e Celeida Silva, intitulado "Implications of concomitance in technical education financed by Pronatec in the Mato Grosso 
do Sul State education network (2012-2015)", sobretudo para se aquilatar do peso de certas medidas de política educativa numa verdadeira democratização e no combate à evasão e reprovação.

Igualmente, a reivindicação da autonomia, tão acarinhada nas prescrições da Educação, pode ser encarada como uma posologia de amplo espectro na medida em que a sua invocação pode tratar de várias maleitas relacionadas com fracturas, deficiências e insuficiências do sistema educativo e das escolas, corrigindo-as "ortopedicamente" como se de produto natural se tratasse (ESTÊVÃO, 2013a, p. 81). Convém não esquecer que a autonomia (tal como a descentralização) surgiu em vários países em resposta às reformas educativas "que prometiam um mundo educativo feliz em que as escolas se converteriam em unidades independentes e autogeridas, competindo entre elas por recursos, prestando contas do seu labor, remunerando os professores de acordo com o que produzissem e avaliando os alunos, segundo parâmetros rigorosos e padrões de excelência internacionais." (ESTÊVÃO, 2013a, p. 81). Acresce que, na autonomia, o controlo do Estado exerce-se e apresenta-se, frequentemente, como um "controlo sem mãos". Neste caso, posso concluir que a ideologia da autonomia acaba por aumentar a sensação de poder dos indivíduos, ao mesmo tempo que os torna mais dóceis e disciplinados. Em síntese: ela "é o panóptico da moderna organização educativa" (BALL, 2001, p. 86).

Também a ideologia da equidade, não obstante a sua nobreza, merece algumas considerações (reler com atenção o artigo, nesta Ensaio, de Gerardo Serpa \& Adriana Falcón, intitulado "Masificación, equidad, educación superior"), uma vez que, a partir de certo momento (sobretudo por influência do pensamento liberal), começou a substituir o conceito de justiça, como se este se limitasse à dimensão formal e a equidade contemplasse não apenas a igualdade mas também a diferença. Ora, a vulgarização do conceito de equidade, em certos contextos culturais, pode representar uma cedência a propósitos mais individualistas em detrimento da justiça social e das suas dimensões mais redistributivas; pode significar, como acontece, por vezes, a valorização das dimensões do mérito individual, ou seja, da ideologia da meritocracia. Em resumo, o conceito de equidade tende a apresentar-se, em determinados contextos e tradições, como mais vinculado à produtividade económica e à contribuição individual, pelo que se exige, desde logo, vigilância crítica relativamente ao seu uso. Isto significa que, no actual contexto de invasão da ideologia de mercado, a equidade (tal como a problemática da inclusão, por exemplo) não tem sido vista como indiferente à tensão entre a agenda democrática e a agenda neoliberal, sabendo-se que neste confronto, a questão das desigualdades, por exemplo, tenda a ser esquecida a favor de outras problemáticas. 
Ainda para reforçar a coluna vertebral do sistema e a saúde organizacional das escolas e dos professores, também hoje se aponta (e alguns artigos deste número da Ensaio aludem a aspectos destes tópicos) para que o sistema proceda à prestação de contas, privilegie culturas de aprendizagem, favoreça auditorias, dê relevo à individualização dos processos formativos e à formação flexível, destaque a omnipotência das tecnologias, sublinhe a imprescindibilidade da avaliação e a publicação de metas, resultados e de rankings. Estas parecem ser, para muitos, tecnologias "sem contra-indicações" e com efeitos sanitários, terapêuticos e morais incontestáveis, que irão certemente endireitar o sistema educativo. Os mais condescendentes consideram até que, apesar de tudo, poderá verificar-se eventualmente algum efeito colateral, mas que uma posologia certa, prescrita pelos peritos, especialistas e tecnólogos educativos altamente treinados, tudo ultrapassará a contento de todos. Particularmente elucidativa deste tópico é a questão da avaliação, que, hoje em dia, serve para tudo, para avaliar tudo e nada, num surto que já apelidei de "avaliacionite aguda", que intenta credibilizar o sistema e os actores sem, muitas vezes, trazer nada de novo, a não ser a alteração de práticas, quantas delas epidérmicas, para se ajustarem às novas exigências ou aos novos padrões - nacional ou internacionalmente - requeridos.

Finalmente, gostaria de destacar mais uma ideologia de conveniência: a ideologia da qualidade, tantas vezes enaltecida como a poção mágica para todas as imperfeições do sistema educativo. Ora, apesar dos seus méritos (que não nego e que são patentes em alguns dos trabalhos deste número da Ensaio), não posso deixar de sublinhar também o que a sua agenda poderá ocultar, nomeadamente quando ela é assumida em termos produtivistas, eficientistas e mercadológicos. Com efeito, a qualidade da educação, por mais critérios quantitativos que se apresentem para defini-la e entendê-la, não deixará de ser também uma questão importante de enobrecimento do ser humano, a não ser que a rebaixemos a uma qualidade corrompida, pensada de maneira eficientista, ajustada aos nossos interesses e ambição. Mais. Como já acentuei noutro lugar (ESTÊVÃO, 2013b, p. 23), a propósito precisamente da qualidade em educação, ela é multifacetada e pode assumir vários sentidos:

Assim, é possível afirmar que a questão da qualidade é uma questão de opção (política) por um determinado tipo de qualidade, em detrimento de outras qualidades que poderiam ser consideradas. $\mathrm{Ou}$ seja, ela transmuta-se consoante o apelo se faça à lógica do mundo industrial para valorizar o capital humano; à lógica do mundo cívico para salientar a promoção da igualdade, da solidariedade e da justiça diante do ensino; à lógica do mundo doméstico em nome da maior proximidade relacional, do cuidado a dispensar 
aos atores escolares, favorecendo a aprendizagem; à lógica do mundo mercantil, tendo em vista o incremento dos padrões de produtividade e competitividade.

Neste último cenário (da prevalência do mundo mercantil), por exemplo, faz todo o sentido falar num tipo especial de qualidade, que está conectada com as vantagens competitivas, com a criação de distintividade, com a satisfação das necessidades soberanas do cliente, com a criação de nichos que respondam à diversidade de demandas na área do consumo da educação.

Considero, por isso, que, quando lidamos com estas ideologias de conveniência, é fácil ser seduzido pelo encantamento dos próprios conceitos e pelas vozes, quase uníssonas, que apregoam aos quatro ventos as suas incomensuráveis virtudes. Porém, se revirarmos os conceitos e as ideologias, para lermos o seu lado escondido, podemos chegar à conclusão de que há outras "verdades" que merecem ser desocultadas, mas que exigem não nos deixarmos cair na tentação, quer da ingenuidade política que nos leva a aceitar tudo como inevitável e definitivo, quer da nossa transformação em crentes de uma teologia política, mesmo que progressista, que nos torna prosélitos de verdades inconfessadas e defensores acéfalos de caminhos de salvação prometidos por deuses obscuros.

Dito de outra forma e em tom Foucaultiano, defendo que muitas destas ideologias têm funcionado na educação como tecnologias subtis de poder, como práticas disciplinadoras, que nos tornam mais dóceis e disciplinados, e que, como benefícios colaterais, nos prometem milagres de regeneração e até, finalmente, a bem-aventurança futura de uma educação esmerada, bem ajustada, multimodal e multiusos. Ora, o problema que poderá colocar-se aqui é saber se a educação, imortalizada por alguns crentes da ideologia de mercado, perfeitamente sintonizados com o novo espírito do capitalismo actual que aponta para a constituição de um novo tipo de indivíduo, não ficará à deriva, sem razão e sem alma.

\section{Referências}

BALL, S. Cultura, costes y control: la autonomia y la enseñanza de caraácter empresarial en Inglaterra y Gales. In: SMITH, J. (ed.). La autonomia escolar: una perspectiva critica. Madrid: Akal, 2001. p. 77-97.

ESTÊVÃO, C. V. Políticas de educação e autonomia: algumas reflexões perversas sobre temáticas abençoadas. Educação: Temas e Problemas, n. 12-13, p. 77-88, $2013 \mathrm{a}$. 
ESTÊVÃO, C. V. (2013b). A qualidade da educação: suas implicações na política e na gestão pedagógica. Revista Brasileira de Política e Administração da Educação, v. 29, n. 1, p. 15-26, jan/abr. 2013b. https://doi. org/10.21573/vol29n12013.42818

HARTLEY, D. El estado evaluador y la autonomia de la educación: motivo de reflexión?. In SMITH, J. (ed.). La autonomia escolar: una perspectiva critica. Madrid: Akal, 2001. p. 119-137.

\section{Informações do autor}

Carlos Vilar Estêvão: Doutor pela pela Universidade do Minho; Editor Associado da revista Ensaio: Avaliação e Políticas Públicas em Educação; Professor Catedrático convidado da Universidade Católica Portuguesa. Contato: cestevao@ie.uminho.pt

iD http://orcid.org/0000-0002-5344-0638 